\title{
Undergraduate Students' Mathematical Proof Processes in a Calculus Course: A Case Study
}

\author{
Meltem SARI* Arif ALTUN ${ }^{* *}$ Petek AŞKAR ${ }^{* * *}$
}

\begin{abstract}
This qualitative case study is designed to determine students' views on and processes of constructing proofs. The participants were two females and one male freshman students in a mathematics teacher training program. The participants were selected representing their proficiency level in Intro to Analysis II as low, medium and high achievers. Data were gathered through classroom observations, structured interviews and papers where students reflected their proof processes. The data were analyzed through content analysis by using a qualitative analysis software program, Nvivo 7. The findings describe students' proof schemes and approaches, as well as display the patterns in showing the relationship between proof schemes and approaches.
\end{abstract}

Key Words: calculus, proof, mathematics education, undergraduate students

\footnotetext{
* Arş. Gör. Hacettepe Üniversitesi Eğitim Fakültesi OFMA Eğitimi Bölümü meltem-s@ hacettepe.edu.tr 03122976104

** Doç. Dr. Hacettepe Üniversitesi Eğitim Fakültesi Bilgisayar ve Öğretim Teknolojileri Eğitimi Bölümü altunar@hacettepe.edu.tr 03122976217

*** Prof. Dr. Hacettepe Üniversitesi Eğitim Fakültesi Bilgisayar ve Öğretim Teknolojileri Eğitimi Bölümü paskar@hacettepe.edu.tr 03122977176
} 


\section{SUMMARY}

Purpose and significance: The purpose of this study is to determine students' views on and processes of constructing proofs. Existing literature reports students' views and ideas about proof (e.g., Raman, 2003), thinking styles (e.g., Almeida, 2000), approaches to proof production (e.g., Weber, 2004b) and their proof schemes (e.g., Harel\&Sowder, 1998). It is crucial to investigate students' difficulties in constructing proofs in order to guide students on the way of acquiring proof construction and to develop instructional materials. Therefore, there is a need to conduct cognitive-based research (see, Hart 1994, cited in Weber, 2001). In this study, students' proof construction processes were investigated to explore the cognitive patterns between their proof production approaches and proof schemes.

Methods: This case study has been conducted in Intro to Analysis II course with freshmen in the department of mathematics education during 2006-2007 academic year. The participants were selected representing their proficiency level in Intro to Analysis II as low, medium and high achievers. Data were gathered through classroom observations, structured interviews and papers where students reflected their proof processes. Researcher attended the course throughout the semester and kept observational notes to describe the course flow and classroom environment. Two structured interview sessions were held with students about their views on proof construction and the course itself. In the first interview, a pre-prepared interview form was used whereas in the second interview, a mathematical theorem was given to students to construct its proof. The interview sessions were video and tape recorded. The data were transcribed and entered into Nvivo 7 qualitative software analysis program. A content analysis has been done to observe the emerging codes in students' views on proof production process and proof schemes.

Results: The findings indicate that high achiever participant tended to use transformational proof scheme and reached a valid proof by using syntactic proof production. Medium achiever participant started with inductive and switched to transformational proof scheme toward the end. $\mathrm{He}$ reached a valid proof by using procedural proof production. Low achiever participant performed both authoritative and perceptual proof scheme characteristics. She used procedural proof production, yet did not reach a valid proof.

Discussion and Conclusions: The findings support the idea that students' success in Intro to Analysis course is parallel to their proof construction success. This finding can be interpreted as students' approach to the course might be related to their approach to proof construction. This study is limited to a single theorem with three participants at three different levels; therefore, more research is needed to further explore the patterns in students' proof construction processes with different variables. 


\title{
Üniversite Öğrencilerinin Analiz Dersi Kapsamında Matematiksel Kanıtlama Süreçleri: Örnek Olay Çalışması
}

\author{
Meltem SARI* Arif ALTUN** Petek AŞKAR ${ }^{* * *}$
}

ÖZ. Bu çalışmanın amacı öğrencilerin kanıtla ilgili görüşlerini belirlemek ve kanttlama süreçlerini incelemektir. Nitel olarak desenlenen bu çalışma bir durum çalışmasıdır. Çalışmaya ikisi kız biri erkek üç öğrenci katılmış, hepsi matematik öğretmenliği birinci sınıf öğrencileridir. Katılımcılar, Analize Giriş II dersi kapsamında düşük, orta ve yüksek başarı gösteren öğrenciler olarak çalışmaya seçilmişlerdir. Veriler, ders gözlemleri, öğrencilerle yapılan görüşmeler ve görüşmede sorulan ifadeyi kanıtladıkları kâğıtlardan oluşmaktadır. Verilere içerik analizi uygulanmış ve görüşmeler Nvivo 7 programında kodlanmıştır. Çalışmada öğrencilerin sahip oldukları kanıt şemaları ve kanıt yapma yaklaşımları belirlenmiş, farklı başarı seviyesindeki öğrencilerin kanıt şemaları ve kanı yapma yaklaşımlarının arasında nasıl bir bilişsel örüntü olduğu araştırılmıştır.

Anahtar sözcükler: analiz dersi, kanıt, matematik eğitimi, üniversite öğrencileri

\footnotetext{
* Arş. Gör. Hacettepe Üniversitesi Eğitim Fakültesi OFMA Eğitimi Bölümü meltem-s@ hacettepe.edu.tr 03122976104

** Doç. Dr. Hacettepe Üniversitesi Eğitim Fakültesi Bilgisayar ve Öğretim Teknolojileri Eğitimi Bölümü altunar@hacettepe.edu.tr 03122976217

*** Prof. Dr. Hacettepe Üniversitesi Eğitim Fakültesi Bilgisayar ve Öğretim Teknolojileri Eğitimi Bölümü paskar@hacettepe.edu.tr 03122977176
} 


\section{GİRis}

Bugün anlaşıldığı anlamıyla kanıtın kaynağını M.Ö. IV. yüzyılda yayınlanan, Euclid'in "Elements"i oluşturmaktadır. Matematiksel kanıt; bir sonucu doğrulamak, başkalarını bilgilendirmek ve bu bilgiye ikna etmek, bir sonuç bulmak ve sonuçları tümdengelimsel bir sistem içine yerleştirmek için kullanılır (Almeida, 2003).

Matematik kanıtlama disiplinidir ve bu özelliği matematik ile diğer disiplinler arasındaki temel farkı açıklar. Aksiyomlar, tanımlar, varsayımlar, teoremler ve teoremin kanıtları bilimsel bir disiplin olarak matematiğin yapı iskeletini oluşturur (Heinze\&Reiss, 2003). Matematik derslerinde kanıtlamanın önemi ve rolü nedeniyle, özellikle yüksek matematik öğreniminde, üzerinde oldukça zaman harcanan bir konudur. İleri düzey matematik derslerinin öncelikli amacı, öğrencilere kanıtlama becerisini kazandırmaktır ve öğrencilerin kanıtlamadaki yeterlikleri, performanslarının bir değerlendirmesi olarak görülür (Weber, 2001). Matematiksel kanitlama bu kadar önemli olmasına ve lisans eğitiminde üzerinde durulmasına rağmen üniversitede yüksek matematik gören öğrenciler kanıtlamada güçlük çekmektedirler (örn. Moore, 1994; Harel\&Sowder, 1998; Dreyfus, 1999; Almeida, 2000; Jones, 2000; Weber, 2001; Recio\&Godino, 2001; Weber, 2004b; Stylianides, Stylianides and Philippou, 2007).

Son y1llarda, matematik derslerinde akıl yürütme, kanıt ve muhakeme gibi konular, matematik eğitimi araştırmalarında ön plana çıkmaktadır (Heinze\&Reis, 2003). Yurtdışında, öğrencilerin, öğretmen adaylarının ve öğretmenlerin kanıt ile ilgili görüşlerini, kabullenmelerini ve kanıtlama süreçlerini ortaya çıkarmaya yönelik olarak çok sayıda araştırma yapılmıştır (örn. Jones, 1997; Harel\&Sowder, 1998; Almeida, 2000; Jones, 2001; Recio\&Godino, 2001; Raman, 2001; Weber, 2001; Knuth, 2002; Raman, 2002; Almeida, 2003; Raman, 2003; Solomon,2006; Stylianides, Stylianides and Philippou, 2007) . Öğrencilerin kanıtlamada karşılaştıkları güçlüklerin nedenlerini belirlemeye yönelik çalışmalar, lise ve üniversite düzeyinde, öğrencilerin sadece kanıtlamada değil, kanıtın ne olduğunu hatırlamada bile zorluk yaşadığını göstermektedir (örn. Chazan, 1993, Moore, 1994; akt. Raman, 2003). Ülkemizde ise bu alanda yapılmış sınırlı sayıda çalışma bulunmaktadır. Özer ve Arıkan (2002) çalışmalarında lise iki ögrencilerinin kanıtlama becerilerinin istenilen düzeyde olmadığını gözlemişlerdir. Benzer şekilde Güven, Çelik ve Karataş (2005) ortaöğretimde öğrenim gören çocukların farklı geometri konularında kanıtlama becerilerinin yetersiz olduğu sonucuna ulaşmışlardır. Öğretmen adayları ile yapılan çalışmada ise öğretmen adaylarının kanıtlamaya yönelik görüşlerinin tam oluşmadığı, kanıtlamanın matematik ve matematik öğretimi açısından önemini bilmedikleri görülmüştür (Moralı, Uğurel, Türnüklü ve Yeşildere, 2006). 
Aydoğdu, Olkun ve Toluk (2003) alt1, yedi ve sekizinci siniflardan dörder öğrenci ile gerçekleştirdikleri çalışmalarında, ilköğretim öğrencilerinin çözdükleri matematik problemlerinin doğruluğunu gösterirken Harel ve Sowder'ın (1998) sinıflamasına göre hangi kanıt şemalarını kullandıklarını araştırmışlar ve öğrencilerin dışsal, deneysel ve analitik şemalardan üçünü de kullandıklarını gözlemişlerdir.

Weber (2001), öğrencilerin ileri matematik konularında kanıt yapma ile ilgili yaşadıkları güçlükleri, yapılan çalışmalar doğrultusunda, iki açıdan değerlendirmektedir. Bunlardan ilki, öğrencilerin matematiksel kanıtın nelerden oluştuğu hakkında doğru bir fikre sahip olmadıkları düşüncesidir. Örneğin, bazı öğrencilere göre, teoremin bir veya birkaç örnek için doğruluğunu göstermek yeterli bir kanıttır. İkinci olarak, öğrenciler bir kavramı veya teoremi anlamada ve sistematik olarak bunu uygulamada eksik kalabilmektedirler. Öğrencilerin bir gerçeği veya teoremi hatırlaması, bunu uygun şekilde uygulamalarını sağlamamaktadır.

Moore (1994) ise matematik veya matematik eğitimi okuyan üniversite öğrencileri ile yaptığ 1 çalışmasında, öğrencilerin kanıtlamada karşılaştıkları güçlüklerin kaynağını belirlemeye çalıșmıș ve bunların en önemlilerinin 1) kavramı anlama 2) matematiksel dil ve notasyon ve 3) kanıta başlama olduğunu görmüştür.

Raman (2003) üniversite öğrencileri ve öğretmenlerinin kanita bakışlarını incelemiş ve kişilerin kanıtlama ve kanıtı değerlendirmelerinde üç farklı düşünce biçimi tanımlamıştır. Bunlar, buluşsal düşünce, prosedürel düşünce ve anahtar düşünce olarak isimlendirilmiştir. Buluşsal (heuristic) düşünce informal anlamalara dayanır. Örneğin, deneysel veriye dayandırılır veya şekille gösterilir. Anlaml olabilir ama formal kanıta götürmez. Buluşsal düşünce bir şeyin doğru olduğuna dair bir his verir ama ikna etmez. Prosedürel düşünce ise kanıtlamada kullanılır ve informal anlamalarla bağlantı kurmaksızın, mantık ve formal kanita götüren formal manipülasyonlara dayalıdır. Prosedürel düşünce bir şeyin doğru olduğunu gösterir ikna hissi verir ama anlama hissi vermez. Anahtar düşünce, uygun mantıksal geçerlikle birlikte formal kanıta dönüştürülebilen buluşsal düşüncedir. Hem anlama hem de ikna hissi verir. Buluşsal düşünce özel, prosedürel düşünce geneldir ve anahtar düşünce bunların ikisi arasında bağlantı sağlar.

Almeida (2000), üniversite öğrencileriyle yaptı̆̆ çalışmasında, görüşmelerin sonunda öğrencilerin kanıtla ilgili algılarını dört tipte sinıflandırmıştır.

Tip A: Öğrenci formal kanıtın gerekliliğini kabul eder ve informal kanitı red eder. 
Tip B: Öğrenci formal kanıtın gerekliliğini kabul eder ancak formal kanıtlarda usta olana kadar geçici olarak informal kanıtları kullanır.

Tip C: Öğrenci sezgisel ve deneysel argümanları kanıt olarak kabul eder.

Tip D: Öğrenci formal kanıtın gerekliliğini kabul eder ama genellikle bunu sembolik manipülasyon olarak görür.

Weber (2004b) de ileri matematik derslerinde lisans öğrencilerinin kanıtlamada kullandıkları farklı yaklaşımları tanımlamaya çalışmıştır. $\mathrm{Bu}$ yaklaşımlar: prosedürel kanıt yapma, sentaktik (syntactic) kanıt yapma ve semantik kanıt yapma olarak belirlenmiștir. Prosedürel kanıt yapma, kişinin öngörülmüş olan eylem ve süreçleri takip ederek kanıt oluşturmasıdır ve kişi bu şekilde geçerli bir kanıt oluşturacağına inanır. Öğrenci kanıtı prosedürel olarak yaptığında, elde ettiği sonucun kanitlanması gereken durumu nasıl gösterdiğinin farkında olabilir veya olmayabilir. Sentaktik kanıt yapma ise doğru bir şekilde ortaya konan tanımların ve ilişkili diğer gerçeklerin, mantıksal olarak kabul edilebilir bir yolla manipüle edilmesiyle yazılan kanıttır. Sentaktik kanıt yapmada kanıtlayan kişi diyagramları veya formal olmayan gösterimleri kullanmaz. Semantik kanıt yapma sürecinde kanitlayan kişi yaptığı formal çıkarımları öne sürmek ve ifade etmek için durumun uygulandığ matematiksel nesnelerin gösterimlerini kullanır. Mesela $\{1,0,1,0,1, \ldots\}$ dizisinin yakınsak olmadığını kartezyen düzlemde çizerek gösterir (bkz., Weber, 2004a; Weber, 2004b; Weber\&Alcock, 2004).

Kanıtlama ile ilgili farklı düşünceler ve yaklaşımlar olsa da, bir durumu kanıtlamaları istendiğinde profesyonel matematikçilerin ve uygun yeterlikteki matematik öğrencilerinin hepsinin, kanttlanan durumla sonuçlanan ve mantıksal geçerliği olan bir argüman ortaya çıkarmak gibi ortak bir amacı vardır. Ancak, öğrenenlerin genel bilgileri ve kanıtla ilgili bilgileri aynı olmayabileceğinden (örn., üniversite öğrencilerinin kanıt kavramı lise öğrencilerinkinden; günümüz matematikçilerinin kanıt kavramları da eski dönemlerdeki matematikçilerinkinden farklıdır, bkz., Harel \& Sowder, 2007), bu amaca ulaşırken farklı süreçler kullanabilirler (Weber\&Alcock, 2004).

Harel ve Sowder (2007) bir kişinin veya topluluğun kanıt kavramını açıklamak için kanıt şeması terimini tanımlamışlardır. Kanıt şeması; kişinin kendini ve diğerlerini bir matematiksel durumun doğruluğuna veya yanlışlığına ikna etmede kullandığı argümanlardır. Harel ve Sowder (1998) kanıt şemalarını şu şekilde sınıflandırmışlardır:

Dışsal ikna kanıt şemaları: Kişi kendini ve diğerlerini dişsal bir şey kullanarak ikna eder. Üç sınıfa ayrılır. 
- Otoriter kanıt şeması: Kişi öğretmenin, kitabın veya başka bir otoritenin söylediğine dayalı olarak ikna olur.

- Ritüel (ritual) kanıt şeması: Burada ikna edicilik, kanıtın içeriğine değil biçimine dayalıdır.

- Sembolik kanıt şeması: Sembolik kanıtta ikna edicilik, anlamını bilmeden sembolik manipülasyonla olur.

Deneysel kanıt şemaları: Deneysel kanıt şemaları tümevarımsal veya algisal olabilir.

- Tümevarımsal kanıt şeması: Bu kanıt şemasına sahip olan öğrenci, genel durumun doğruluğuna ikna edici delil olarak, bir veya daha çok örneği göz önünde bulundurur, argümanlar özel durumlara ve örneklere dayanır.

- Algısal kanıt şeması: Öğrenci, tümdengelimden sağlanmamış, yetersiz zihinsel gösterimlere dayalı çıkarımlar yapar ve bu çıkarımların kendisi ve diğerleri için ikna edici olduğunu düşünür.

Analitik (çıkarımsal-tümdengelimsel) kanıt şemaları: Dönüşümsel veya aksiyomatik olabilir.

- Dönüşümsel (transformational) kanıt şeması: Bu kanıt şemasında öğrenci kendini ve başkalarını çıkarımsal bir süreçle ikna eder. $\mathrm{Bu}$ süreçte öğrenci genellenebilir durumları göz önünde bulundurur; amaca yönelik zihinsel operasyonları uygular; tanımlar, teoremler ve şekiller arasında geçişler yapar. Üç özelliği vardır: genellenme, operasyonel düşünme ve mantıksal çıkarım.

- Aksiyomatik kanıt şeması: Bu şema, dönüşümsel kanıt şemasının özelliklerine sahiptir ve bu özelliklere ek olarak öğrenci, matematiksel sistemlerin kanıtsız olarak kabul edilen durumlara dayandığını fark eder (bkz., Housman\&Porter, 2003; Harel\&Sowder, 1998; Harel\&Sowder, 2007; Knapp, 2005 ).

Bütün bu çalışmalara bakıldığında çeşitli modellerin ve kanıt yaklaşımlarının ortaya konmuş olduğu görülmektedir. Çalışmalar, öğrencilerin kanıtı algılayışlarını, kanıtlamadaki düşünme biçimlerini, kanıt yapma yaklaşımlarını ve sahip oldukları kanıt şemalarını tanımlamaya yöneliktir. Hart'a göre (1994) öğrencilerin kanıtlama süreçlerini ve bu süreçte düştükleri hataların nedenlerini doğru bir şekilde ortaya koyabilmek için kanttlama ile ilgili, öğrencilerin düşünme süreçlerini incelemeye yönelik, bilişsel tabanlı çalışmalar yapılması gerekmektedir (akt. Weber, 2001). 
Ayrıca, öğrencilerin çoğu nasıl kanıtlayacağını, kanıtlamaya nerden başlaması gerektiğini, kanıtlama sürecinde kullanması gereken kavramsal bilgileri, tanımları ve bunları nasıl kullanması gerektiğini bilmemektedir. Öğrencilerin kanıtlarken düştükleri hataların nedenini anlamak için öğrencilerin kanıtlama süreçlerini incelemek gerekmektedir (Weber, 2001). Dolayısı ile bu çalışmada farklı başarı seviyesindeki öğrencilerin kanıtlama süreçleri incelenmiştir. $\mathrm{Bu}$ amaçla, bu çalışmada "öğrencilerin kanıt yapma yaklaşımları ve kanıt şemalarında nasıl bir bilişsel örüntü bulunmaktadır" sorusuna cevap aranmiştır.

\section{YÖNTEM}

\section{Araștırmanın Bağlamı}

Çalışma 2006-2007 akademik yılı bahar döneminde matematik eğitimi anabilim dalı birinci sınıf öğrencileriyle Analize Giriş II dersi kapsamında yürütülmüştür. Dersler haftada iki gün ve üçer saat olarak 12 hafta boyunca sürmüştür. Analize Giriş dersi haftada 4 saat teorik, 2 saat uygulamalı olarak yapılan, birinci sınıfın en yoğun dersidir. Ders güz dönemindeki Analize Giriş I dersinin devamı niteliğgindedir.

Gözlem yapılan ders, ileri matematik derslerinin alışılmış yapısına uygun olarak, öğretmenin gerekli bilgileri vermesi, konuyu anlatması ve öğrencilerin not alması şeklinde ilerlemektedir. İleri matematik derslerinin genellikle "tanım-teorem-kanıt" biçiminde işlendiği gibi bir ortak kanı bulunmaktadır (Weber, 2004c). Söz konusu derste de, öğretmen, tanım ve teoremleri verip kanıtları açıklayarak yapma ve konu içeriğine bağlı olarak değişik türde sorular çözme biçiminde bir öğretim uygulamıştır. Dersin teorik kısımlarında, öğretmen anlatırken öğrenciler not tutmakta, uygulama ağırlıklı bölümlerde ise öğretmen tahtaya sorular yazıp çözmektedir. Öğrenciler bazen anlamadıkları yerleri sorarak veya öğretmenin sorduğu sorulara oturdukları yerden yanıt vererek derse katılmaktadırlar (Gözlem notu).

Weber'e (2004c) göre matematik dersinin amacı; öğrencileri, ilgili konudaki matematiksel kavramlarla ayrıntılı kanitlar yapabilecek duruma getirmektir. Weber (2004c) geleneksel yaklaşımda işlenen derslerde şu özelliklerin gözlendiğini belirtmiştir: dersin hocası konuyu anlatır ve öğrenciler pasif bir şekilde not alırlar; ders mantıklı bir sırayla sunulur, konunun verilen sezgisel nitelikleri üzerine mantıksal özellikleri, mesela formal tanımlar, ayrıntılı kanıtlar, örnek olarak verilir. Çalışmanın yapıldığı Analize Giriş II dersinin de bu yaklaşımla işlenen bir ders olduğu söylenebilir. 


\section{Katılımcilar}

Çalışmanın katılımcıları, 2006-2007 öğretim yılında Ankara'daki bir üniversitenin matematik öğretmenliği bölümünde birinci sınıfta öğrenim gören ve sınıf içi gözlemler, ders öğretmeniyle yapılan görüşmeler, sınav kâğıtlarının değerlendirilmesine göre düşük, orta ve yüksek başarı seviyesinde olan ikisi kız biri erkek üç öğrencidir. Çalışmada Didem yüksek, Mert orta ve Ceren düşük başarı seviyesindeki öğrenci olarak yer almaktadır. Öğrencilerin gerçek isimleri gizli tutulup onun yerine araştırmacı tarafından isim verilmiştir. Öğrenciler güz döneminde Analize Giriş I ve tanım, teorem, kanıt ağırlıklı bir içeriği olan Soyut Matematik I derslerini tamamlamışlardır. Öğrenciler kanıt ile ilk defa ve yoğun olarak üniversitede karşılaşmışlardır.

\section{Verilerin Toplanması}

Çalışmada kullanılan veriler, öğrencilerle yapılan görüşmeler, ders gözlemleri ve öğrencilerin kanıtlarının bulunduğu kâğıtlardan oluşmaktadır. Araştırmacı çalışmanın geçtiği Analize Giriş II dersini bir dönem boyunca takip etmiştir. Takip edilen derslerin ikisi için gözlem raporu yazılarak dersin işlenişinin ve sınıf ortamının betimlemesi yapılmıştır. Öğrencilerin her biriyle, birebir olarak üniversitede boş bir sınıfta ikişer görüşme yapılmıştır. İlk görüşme, öğrencilerin, dersin genel işlenişi ve kanıt yapma hakkındaki görüşlerini belirlemek üzere yapılmış ve ses kaydı alınmıştır. Bu görüşmede araştırmacı tarafindan hazırlanan yapılandırılmış görüşme formu kullanılmış ve öğrencilere "Dersin işlenişi ile ilgili neler düşünüyorsun? Dersin teorik mi uygulama ağırlıklı mı olduğunu düşünüyorsun? Sen hangi kısma daha çok ilgi duyuyorsun? Kanıt yapma ile ilgili ne düşünüyorsun?" türünde sorular yöneltilmiştir.

İlk görüşmeden birkaç hafta sonra ve öğrencilerin ikinci sınavlarının yapılmasının ardından ikinci görüşme gerçekleştirilmiştir. Bu görüşmede öğrencilere aşağıdaki matematiksel ifade verilerek, kanıtlamaları istenmiştir.

“Önerme: $f:[a, b] \rightarrow R$ türevlenebilir bir fonksiyon olsun f'nin monoton artan olması için gerekli ve yeterli koşul $x \in[a, b]$ için $f^{\prime}(x) \geq 0$ olmasıdır."

Öğrencilerden Didem'le yapılan birinci görüşme 17 dakika, ikinci görüşme 22 dakika; Mert'le ilk görüşme 7 dakika, ikinci görüşme 35 dakika; Ceren'le ilk görüşme 15 dakika, ikinci görüşme 52 dakika sürmüştür.

İkinci görüşmede öğrencilere kanıtlamaları için verilen ifade, öğrencilerin ilk dönem konuları kapsamındadır. Seçilen ifadenin derste kanıtlanmamış olmasına ve kitapta da yer almamasına dikkat edilmiştir. $\mathrm{Bu}$ şekilde öğrencilerin var olan kanıtı hatırlayarak yapmalarını önleyip kendi düşünme süreçlerini ortaya çıkarmak amaçlanmıştır. 
Öğrencilerin kanıtlama süreçleri videoya kaydedilmiş ve öğrencilere ihtiyaç duydukları bilgilere bakmaları için ders kitabı verilmiştir. Kanıtlama sürecinde öğrencilerin ne düşündüklerini sesli bir şekilde anlatmaları istenmiştir. Araştırmacı bu süreçte öğrencilerin yanında beklemiş, onları gözlemiş ve öğrencilere, ne yaptıklarını ve ne düşündüklerini sesli olarak ifade etmeleri konusunda hatırlatmalar yapmıştır. Öğrenciler kanıtlamaya çalışırken, yaptıklarının sebeplerini açıklamaları istenmiş ve sonuçta ortaya çıkardıkları kanıtı ikna edici bulup bulmadıkları sorulmuştur. Görüşmenin sonunda öğrencilerin kanıtı yazdıkları kâğıtlar da alınarak matematiksel dil ve notasyonun kullanımı, kanıtın doğruluğu ve öğrencinin ifadeleri bakımından incelenmiştir.

\section{Verilerin Analizi}

Çalışma bir durum çalışmasıdır ve her öğrencinin kanıt yapma süreci ayrı ayrı ele alınıp incelenmiştir. Video ve ses kaydı yapılan iki görüşmenin araştırmacı tarafından çözümlemesi yapılmış ve içerik analizi uygulanmıştır. Görüşmeler Nvivo 7 programında kodlanmış ve bu kodlara göre öğrencilerin kanıtlama sürecindeki kanıt şemaları ve kanıt yapma yaklaşımları belirlenmiştir.

\section{BULGULAR}

$\mathrm{Bu}$ bölümde, gözlem süreçleri ve katılımcıların kanıtlama süreçleri doğrudan aktarımla sunulacaktır. Ayrıca, her bir katılımcı için betimsel verilerin sunumu desteklenecektir.

Didem, sınıfta derse katılım gösteren, çok düzenli not tutan ve sınavlarda yüksek başarı gösteren bir öğrenci olarak çalışmaya seçilmiştir. Didem kanitlama sürecinde, ilk olarak verilen ifadeyi yüksek sesle okudu ve ifadeden anladıklarını, ne yapması gerektiğini açıkladı. Öncelikle ifadede geçen monoton artan tanımına ihtiyaç duydu ve tanımı kitaptan buldu. Didem, ifadede gerek ve yeter koşul bulunduğunu ve bu yüzden ifadenin kanıtını her iki taraftan göstermesi gerektiğini söyledi. Monoton artan tanımını yazdıktan sonra bir süre buradan türeve nasıl geçeceğini düşündü. Daha sonra kitaptan türev tanımına baktı ve tanımları açarak ilerleyeceğini belirtti.

"İfadede gerekli ve yeterli koşul var iki taraflı göstereceğim. Tanımları kullanarak gittim önce monoton artan tanımını yazdım. Türevin de tanımını yazdım. İlk önce $\mathrm{f}$ monoton artan olsun dedim ve tanımı yazdım. Tanımı çok açık gelmedi onu biraz açacağım. Ancak ve ancak dediği için iki taraftan göstereceğim. Fonksiyonun türevlenebilir olduğunu söylediğinden demek ki türev ifadesinde kitaptaki tanımda $\mathrm{x}_{1}$ ve $\mathrm{x}_{0}$ ' 1 monoton artan ifadesindekine göre kullanılabilir hale getirmek için $\mathrm{x}_{1}$ ve $\mathrm{x}_{2}$ dedim işime yarasın diye. (Görüşmeci Notu: 
Didem burada tanımlardaki bazı gösterimleri iki tanım arasında geçiş yapmasın k kolaylaştıracak biçimde düzenledi, tanımlar arası geçişlerle ifadeyi bir taraftan kanttladi). İlk kısmı tamamlamış oldum. Şimdi ikinci kısmı yapacağım ve türevin olmasını kabul edersem, türev tanımındaki limit değeri vardır ve ben bunun 0'dan büyük olduğunu kabul edeyim. Şimdi monoton artan olduğunu göstermeliyim."

İfadenin ilk kısmını gösterdikten sonra diğer tarafını yani türevi sıfırdan büyük olan fonksiyonun monoton artan olduğunu yine tanımları kullanarak, tanımlar arasındaki geçişlerle gösterdi. Didem işlemleri yaptıktan ve kanıtı yazdıktan sonra "Tamam kanitladım, bitti. Şimdi kontrol edeyim" diyerek kanıtını adım adım gözden geçirdi ve bu sırada neler yaptığını açıkladı.

Didem, yapılan ilk görüşmede verilen bir ifadeyi kanıtlamak için izleyeceği yolu şu şekilde açıklamıştır:

"Ya şey onunla ilgili daha önceden gördüğümüz bir teorem var mı diye düşünürüm hani ondan yola çıkayım diyerek, o bana yardımcı olabilir mi diyerek onu düşünürüm. $\mathrm{O}$ teoremi orada kullanamayacaksam da onun kanıtını nasıl yapmıştık diye düşünürüm benzetmeye çalısırım. Yani o konu ile ilgili bütün her şeyi kafamda şey yaparım, kategorilere ayırırım hangisini kullanırım, hangisi daha çok işime yarar, hangisi öğrendiğim konuyla bağlantıllydı, onun ispatı nasıl yapılıyordu, bunu buraya aktarabilir miyim, aynı yolları izlesem diye benzeterek yapmaya çalışırım"

Didem, kanıtta bilinen başka teorem ve kanıtlardan yola çıkarak belli adımları izleyerek sonuca ulaşılacağını belirtmektedir. Kanıtlama sürecinde de ifadeyi okuyup ne yapması gerektiğini belirledikten sonra ihtiyacı olan tanım ve teoremleri belirlemiş, kitaptan bu bilgileri yazarak ifadeleri açmış ve bu ifadeler arasında uygun geçişlerle göstermek istediği sonuca ulaşmıştır.

Kanıtı yazdığı kâğıt incelendiğinde Didem'in verilen ifadeyi önce matematiksel sembollerle yazdığ 1 sonra kanıta başladığı, matematiksel dil ve notasyonu doğru kullandığı ve doğru bir şekilde kanıtladığı görülmüştür. Kanıtın matematiksel olarak doğru olmasının yanında kâğıdı kullanımı ve yazısı oldukça düzenlidir. Şekilde (Bkz. Şekil 1) Didem'in kanıtının bir bölümü, ifadenin bir yönden kanıtı, görülmektedir. 


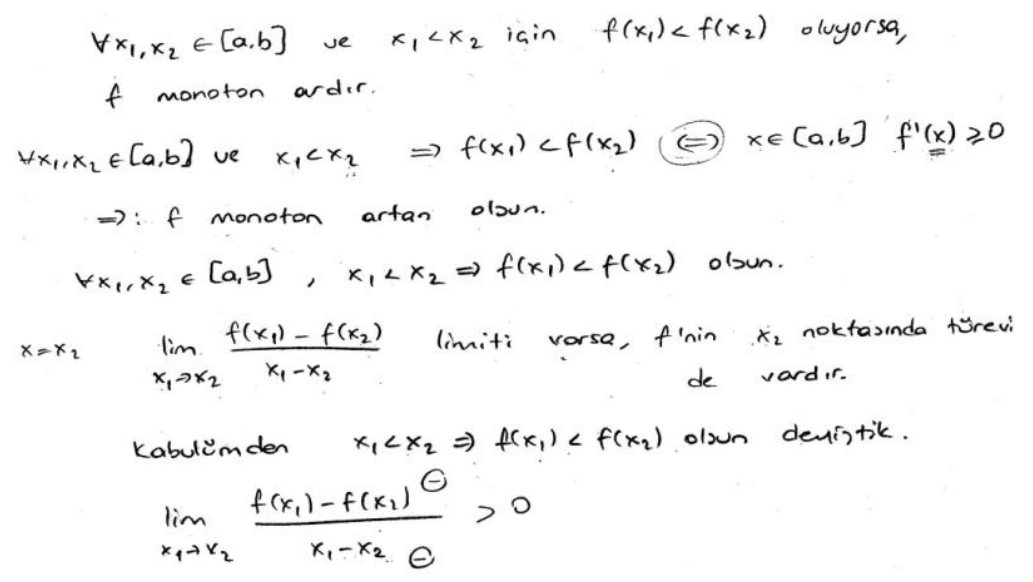

Şekil 1: Didem'in kanıtı

Didem kanıtlarken yüksek sesle düşünmüş ve neler yaptığını kameraya anlatmıştır. Diğer öğrencilerin kanıtlama süreçleri gözlenirken kimi zaman yaptıklarını kontrol edip hatalarını fark etmelerine yönelik sorular sorulmuştur. Ancak Didem için böyle bir şeye gerek duyulmamıştır. Ayrıca diğer iki öğrenciden farklı olarak, kanıtı bitirdikten sonra görüşmeci tarafından bir yönlendirme olmadan kanıtını kontrol etmiş ve yaptıklarının doğru olduğunu düşündüğünü belirtip kanıtı sonlandırmıştır.

Mert, gözlemler sonucu derse sürekli katıldığı, ön sırada oturup not tutarak dersi takip ettiği belirlenen dolayısıyla dersle ilgili olduğu söylenebilecek bir öğrencidir. Öğretmenin görüşü ve sınav kağıdına göre ortalamanın biraz üstü seviyede bir öğrencidir ve çalışmanın orta başarı düzeyindeki katılımcısı olarak seçilmiştir.

Mert, kanıtlaması istenen ifadeyi okuduktan sonra gerek ve yeter koşul olduğu için çift yönlü kanıtlanması gerektiğini ve soyut matematik derslerindeki kanıt yöntemlerinden birini kullanacağını belirtti.

Mert kanita $f(x)=x^{2}+2 x$ şeklinde bir fonksiyon seçerek başladı. Seçtiği bu fonksiyonda $\mathrm{x}$ yerine değerler verdi ve bu şekilde fonksiyonun monoton artan olduğunun görüldüğünü söyledi. Daha sonra fonksiyonun türevini aldı ve $2 x+2$ ' nin çalışılan aralıkta sıfıra eşit veya büyük olması gerektiğini belirtti ve yine değer vererek sıfırdan büyük olduğunu görmeye çalıştı. Ancak bunu tam olarak gösteremedi.

"Analiz dersinde bu tür sorular vardı nasıl yapıyorduk?"

diyerek derste yapılanları ve bu tür sorularda kullandıkları yöntemi hatırlamaya çalıştı. Görüşmecinin, ihtiyacı olan bilgilere bakmak için kitabı 
kullanabileceğini hatırlatması üzerine kitaba baktı. Görüşmeci kitaptan tam olarak neye bakmak istediğini sordu ve Mert

"Nasıl yapıldığına bakıyorum yani bu tarz soruların nasıl yapıldığına şimdi o aklıma gelmedi."

açıklamasını yaptı. Mert aradığı prosedürü bulamayınca “Acaba grafik çizerek mi yapsam " diye düşündü ve seçtiği bir fonksiyonun grafiğini çizerek fonksiyonun artan olduğunu ve türevinin de artan olacağını göstermeye çalıştı. Mert bu şekilde ifadenin seçtiği fonksiyon için geçerli olduğunu gösterdi.

Görüşmecinin bir fonksiyon için göstermesinin yeterli olup olmadığını sorması üzerine Mert yeterli olmadığının farkında olduğunu belirtti.

"Yani tam değil matematiksel olarak bunları matematik diline dökmek gerekiyor. Bana bir fonksiyon verilseydi $\mathrm{f}(\mathrm{x})=\ldots$ diye ve göstermem istenseydi yapardım ama şimdi biraz zorlandım açıkçası. Genel olunca yapmakta zorlanıyorum. Bir de geçen dönemin konusu hatırlamak zor biraz."

Ne yapman gerekiyor peki yeterli olması için?

"Kesinlikle şu tanımdan devam etmem gerekiyor. Monoton artanlık tanımından verilen fonksiyonun türevinin 0'dan büyük olmasını nasıl gösterebilirim. Türevle monoton artanlığın ilişkisi görmedik böyle bir şey."

Mert, tanım ve teoremleri kullanarak kanıtlamaya çalışmak yerine konuyla ilgili önceden yapılmış olan bir kanıtı görmesi gerektiğini düşünmekte ve ilk defa gördüğü bir ifadeyi kanıtlamaya nereden başlayacağını bilmemekte dolayısıyla kanıtlamada güçlük yaşamaktadır.

"Bu soruda bir tarafi doğru kabul edip diğerinin de doğru olduğunu gösterebiliriz ama aklıma gelmiyor nasıl olacağı. Görsem devamını getiririm ama nasıl yapılacağını görmem gerekiyor"

Yapılan çalışmalar öğrencilerin genellikle öğretmenlerinin kullandıkları kanıtlama prosedürlerini kullandıklarını göstermektedir. Öğrenciler kimi zaman nedenini bilmeden sadece öğretmen onun öyle olduğunu söylediği için bazı prosedürleri yerine getirirler (Weber, 2004). Mert'in yaklaşımı da bu şekildedir. Mert kanıtı örneklerle yapmaya çalışmış ancak soyut matematik dersinde kanıtları bu şekilde yapmadıklarını hatırlayarak elde ettiği sonuçtan ikna olmamıştır.

Mert kanıtlama sürecinin büyük kısmında, seçtiği fonksiyon için ifadenin doğruluğunu göstermeye çalışmış ancak görüşmecinin bu şekilde 
yapmasının ikna edici olup olmadığını sorması üzerine ikna olmadığını söyleyip yeniden düşünmeye başlamıştır.

Peki, ifadenin doğruluğunu bir örnek için göstermen kanıtladığın anlamına geliyor mu?

"Hayır, gelmiyor, belki başka örnekte başka fonksiyon için çıkmaz. O yüzden tam ikna etmedi. Ters örnek çıkabilir. Yani soyut matematikte yaptığımız kanıt yöntemleri ile yapılması gerekiyordu."

Mert yaptığından tam ikna olmamaktadır. Sürekli olarak hazır bir yöntem hatırlamaya çalışmakta ve hatırlayamadığı için belli örnekler üzerinde ifadenin doğruluğunu göstermeye çalışmaktadır. Mert sürecin büyük kısmını bu şekilde geçirmiş dolayısıyla formal kanıta dönük bir şeyler yapmamıştır. Mert aslında formal kanıtın nasıl olması gerektiğinin ve kanıtın genel tanımlardan yola çıkarak, örneklere indirgenmeden yapılması gerektiğinin farkındadır ancak bunu yapamadığı için ona daha kolay gelen, ifadenin doğruluğunu örnek üzerinde gösterme yöntemine başvurmaktadır. Mert'in bu davranışı; insanlar kanıtı doğrudan nasıl yapacaklarını bilmiyorlarsa örnekler denemek veya grafiğe bakmak gibi informal yaklaşımlar denerler (Raman, 2002) fikrini desteklemektedir.

“....Yani aklıma fonksiyon seçerek yapmak geldi aslında böyle yapmiyoruz ama unuttum biraz nasıl yaptığımızı. Bu dönemin konusu olsa daha rahat yapardım. Şu anda kanıtı nasıl yapıyorduk onu hatırlayamadım."

Ne yapsaydın ikna oldum derdim?

"Tanımları kullanıp yapsaydım mesela... Şöyle yapabilirdim mesela..."

Tanımları yazarak yeniden kanıtlamaya başladı ve monoton artan tanımını yazdı.

"Monoton artan tanımından türeve nasıl geçeceğiz sonuçta türev bir fonksiyon."

diyerek bir süre düşündü. Mert türevin kavramsal tanımını kullanmayı düşünmemekte, sadece bir fonksiyonun cebirsel olarak türevinin alınmasıyla ortaya çıkan fonksiyonu göz önüne almaktadır. Görüşmecinin türev tanımını düşünmesi konusunda uyarıda bulunması üzerine Mert, kitaptan türev tanımına baktı ve tanımları kullanıp tanımlar arasındaki geçişlerle ifadeyi kanıtladı. Mert sürecin sonunda geçerli bir kanıta ulaşmıştır. 
Ceren derse katılan ama genellikle arka siralarda oturan ve derste kafasına takılan birçok şeyi öğretmene rahatlıkla sorabilen bir öğrencidir. Sınav sonucu ve öğretmenin değerlendirmesine göre ortanın altında bir öğrencidir ve çalışmada düşük başarı seviyesindeki katılımcı olarak yer almaktadır. Araştırmacı Ceren'in görüşmesini çözümlemede diğer öğrencilere göre daha fazla güçlük çekmiştir. Ceren görüşmede düşüncelerini açıklarken karmaşık cümleler ve anlaşılması güç ifadeler kullanmıştır. Sürecin başında Ceren aklına gelen her şeyi, işe yarayıp yaramadığını ayırt etmeden söylemiştir. Daha sonra ise sessizce kendi kendine kağıt üzerinde bir şeyler yapmaya çalışmış ve sürekli kitaptaki tanımlara bakmıştır.

Ceren kanıtlaması gereken ifade verildikten sonra arkadaşlarından farklı olarak ifadeyi sessizce okudu ve

"Şu anda aklıma bir şey gelmiyor tanımları bir yazayım ondan sonra belki bir şey çıkar mı diye bakmaya çalışacağım"

diyerek tanımları yazmaya başladı.

Ne yapıyorsun ne düşünüyorsun şu anda?

"Şu anda ne gerekiyor diye bakıyorum türevli olmassyla monoton artan olması arasındaki bağ aa biz bunu yapmıştı hatırlıyorum...

Gerek ve yeter koşul olduğuna göre tersten gidebilirim. Benim hatırladığım, hayal meyal hatırlıyorum, monoton artanlıkta böyle düzenli bir şey bir grafik vardı ve elimizi kaldırmadan çiziyorduk, kopukluk olmuyordu. O zaman da türevli oluyordu öyle bir şeyler vardı ama aslında bununla alakası olmaması lazım ama."

Ceren kopuk kopuk ve ne olduğu tam anlaşılmayan bazı bilgileri hatırlamaya çalışmaktadır ancak söyledikleri çok net değildi. Aslında tavırlarından ve söylediklerinden düşüncelerinin de çok net olmadığı anlaşılmaktadır.

Uzun bir süre sessizce kitabı karıştırdıktan sonra görüşmecinin neye baktığını sorması üzerine:

"Ben bir bakayım da öylesine"

Aradı̆̆ın belli bir şey var mı?

"Hayır, ne bulabilirim diye bakıyorum"

Ceren kitabı karıştırmaya devam etti ve monoton artan fonksiyonun sürekli olduğunu ve bununla ilgili bir şeyler yapmaya çalıştığını söyledi. Sonra grafik çizerek tanımları şekil üzerinde göstermeye, türevin geometrik 
yorumunu (eğrinin teğetinin eğimi olması) kullanarak çizdiği şekil üzerinde hem artanlığı hem eğimin sıfirdan büyük olduğunu görmeye çalıştı. Ancak Ceren buradan bir şey çıkaramayıp vazgeçti. Ceren'in kağıdı incelendiğinde çizdiği grafiğin matematiksel olarak bir şey ifade etmediği karalama şeklinde olduğu görülmektedir (Bkz. Şekil 2).

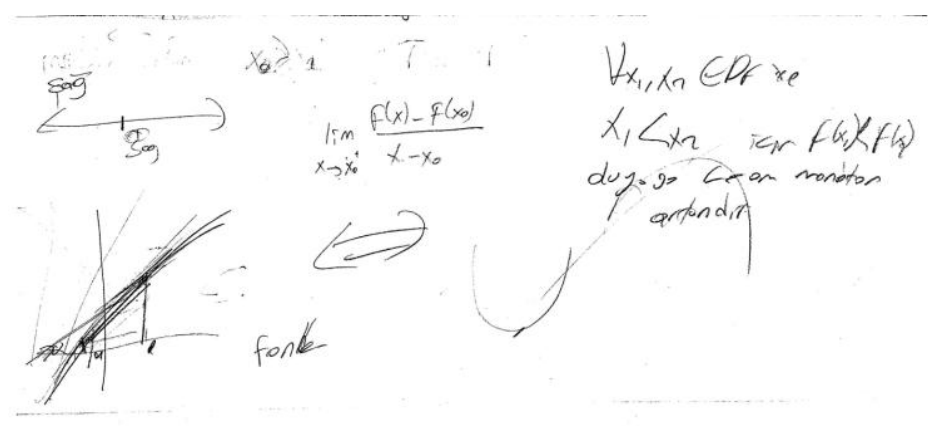

Şekil 2:Ceren'in ilk kanıt süreci

Ceren fonksiyon grafiklerinde eğimle ilgili bir şeyler söyledi ama söyledikleri zor anlaşılmaktadır. Ceren de bu durumu fark edip "Hocam çok mu saçmalıyorum? Öbürleri de böyle düşünmüş müydü?" diye sordu. Davranışı ve söyledikleri, kendinden emin olmadığını ve kanıtla ilgili belli bir düşünce belirleyemediğini göstermektedir. Sürekli, hatırladığ 1 eksik bilgilerle ilgili olarak derste neler yaptıklarını anımsamaya çalışmakta "Aa bunu konunun sonlarında yapmamış mıydık?" șeklinde dersin içeriğine yönelik olarak düşünmekte ve derste yapılanlardan bağımsız bir şekilde, akıl yürüterek kanıtlamak için çaba göstermemektedir. Ceren'in elinde kitap olması ve ihtiyac1 olan bilgilere ulaşma şansı verilmesi geçerli bir kanıt oluşturmasını sağlamamıştır. Weber'in (2001) belirttiği gibi bir gerçeği veya teoremi hatırlamak bunu uygulamak için yeterli olmamaktadır. Ceren'in, bilgiyi kullanma, bağlantıları kurma bakımından da yetersiz olduğu görülmektedir. Ceren'in uzun bir süre bu şekilde bocalaması ve net düşünceler sunamaması ifadeyi bile tam olarak anlayamadığını ve ne yapması gerektiğini bilmediğini göstermektedir. Ceren hatırlamaya çalıştı̆̆ bilgilerden neleri kullanıp neleri kullanmayacağını tam olarak ayırt edememekte, konu ile ilgili her şeyi bir arada düşünmekte ve yapması gerekenleri düzenleyememektedir.

Ceren zamanın büyük kısmını, kanıtlamaktan çok yaptıkları şeyleri hatırlamaya çalışmakla geçirmiştir. Ceren aklına her geleni işe yarayıp yaramayacağını bilmeden söylemektedir. 
Ceren daha sonra "Ben anlatmasam da yazsam olur mu" diyerek kitaptan bazı tanımları kağıda yazmaya başladı. Ceren, kitapta yer alan, türevin teğetin eğimi olması ile ilgili açıklamaya takıldı ve onun üzerinden bir şeyler göstermek için çaba sarf etti. Bu açıklamayı kitaptan alarak kağıda aynen yazdı. Ceren kavramları doğru anlamamıştır ve kavramlar arasında bağlantıları kuramamaktadır. Ayrıca yazdıkları incelendiğinde de matematiksel dili kullanmada yetersiz olduğu görülmektedir (Bkz. Şekil 3).

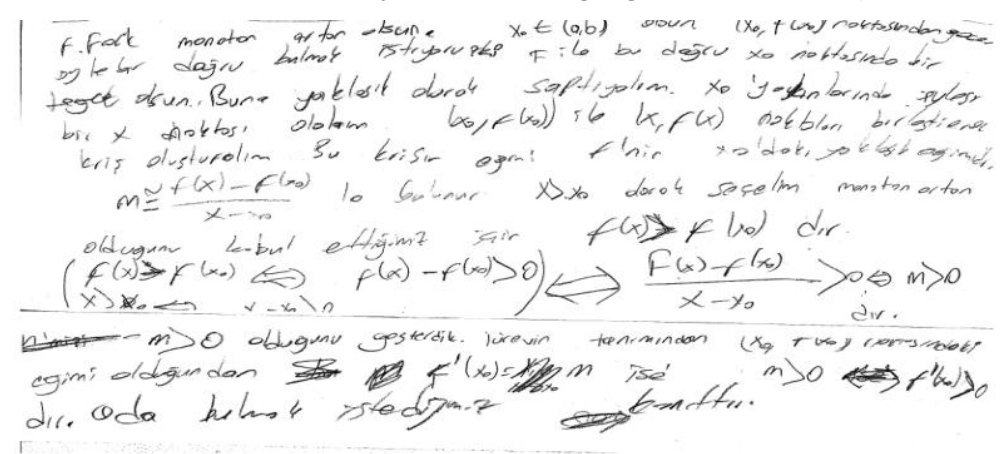

Şekil 3:Ceren'in kanıtı

Ceren'in görüşmesi diğer öğrencilerden daha uzun sürmüş olmasına ve görüşmeci sorular sorarak düşündüklerini toparlamasına yardımcı olmaya çalışmasına rağmen Ceren sürecin sonunda başarılı olamamış ve geçerli bir kanıta ulaşamamıştır.

\section{TARTIŞMA ve SONUÇ}

Öğrencilerle yapılan ikinci görüşmede, öğrencilere matematiksel bir ifade verilerek bu ifadeyi kanıtlamaları istenmiştir. Önceki bölümde de her öğrencinin kanıtlama süreci ayrıntılı bir şekilde betimlenmeye çalışılmış ve öğrencilerin bu süreçte neler yaptıkları açıklanmıştır.

Öğrencilerin kanıtlama süreçlerine baktığımızda, kanıtlama sürecindeki başarılarının analiz dersinde gösterdikleri başarıya paralel olduğu görülmektedir. Yüksek başarılı öğrenci olarak çalışmada yer alan Didem, diğer iki öğrenciye göre daha kısa sürede, görüşmecinin yönlendirmesi olmadan, neler yapması gerektiğini, nasıl yapacağını belirlemiş ve geçerli bir kanıta ulaşmıştır.

Didem kanıtlama sürecinde tanım ve teoremler arasında bağlantılar kurarak ilerlemiştir. Didem'in tanım ve teoremlerden yola çıkarak, amacına uygun geçişlerle formal kanıt yapması Harel ve Sowder'ın (1998) sinıflamasına göre dönüşümsel kanıt şemasına sahip olduğunu göstermektedir. Matematiksel olarak sentaktik kanıt yapma, "tanımları 
açma" ve "sembolleri ilerleterek" kanıt yazma olarak ifade edilmektedir (Weber, 2004b). Didem, Weber'e (2004b) göre değerlendirildiğinde sentaktik kanıt yapma yaklaşımının özelliklerini göstermektedir. Didem, kanıta tanım ve teoremlerle başlamış ve yaklaşımını değiştirmeden, tanım ve teoremler arasında bağlantıları kurarak sonuca ulaşmıştır. Didem'in bu süreçte ne yapması gerektiğini ve bunları yapmak için ihtiyacı olan bilgileri belirlemesi, bilgileri doğru kullanması, geçerli bir kanıta ulaşması ve ortaya çıkan kanıttan ikna olması, yaptıklarını farkında olarak gerçekleştirdiğini göstermektedir.

Sentaktik kanıt yapmanın prosedürel kanıt yapmadan en önemli fark1; prosedürel kanıt yaparken kişiye nasıl ilerleyeceği ile ilgili güçlü rehberlik verilirken sentaktik kanıt yapmada kişinin kendi karar vermesinin gerekmesidir. Ayrıca kanıtı yapan kişi yeni savlar ile kanıttaki eski savlar arasındaki mantıksal bağı açıkça kurmaya çalışır (Weber, 2004a). Bu bakımdan sentaktik kanıt yapmanın prosedürel kanıt yapmadan daha üst düzey düşünme gerektirdiği söylenebilir.

Mert ve Ceren ise kanıtlama sürecinde öncelikle derste bununla ilgili ne yapmış olduklarını hatırlamaya çalışmış, yapmış oldukları benzer kanıtları ya da sorulan ifadenin kanıtını kitaptan bulmak istemişlerdir. Ancak Mert daha önce yapılmış kanıtlar içinden, verilen ifadeye uygulanabilecek genel bir yöntem bulmaya, hatırlamaya çalışırken, Ceren doğrudan kanıtı bulmaya çalışmış ve bulamayınca uzun bir süre kanıtlamaya yönelik olarak herhangi bir şey yapamamıştır. Mert kanıta başlamak için belli bir yöntem olduğunu veya verilen bir kanıt yönteminin benzer başka kanıta uygulanabileceğini ve böyle bir yöntemi kitapta hazır olarak bulacağını düşünmektedir. Buna göre Mert'in önceden öngörülmüş olan eylem ve süreçleri takip ederek kanıtlamaya çalıştığ 1 ve bu şekilde geçerli bir kanıt oluşturacağına inandığ1 söylenebilir. Weber'in (2004b) sinıflandırmasına göre Mert prosedürel kanıt yapma yaklaşımına sahiptir.

Weber (2004b) çalışmasında öğrencilerin iki tip prosedürel kanıt yaklaşımı gösterdiklerini belirlemiştir. Birincisinde prosedür; son derece mekanik ve belli tipte problemlere bağlı bir liste adımdan oluşan algoritmadır. İkincisinde prosedür; özelleştirilmiş manipülasyonlardan çok genel bir amacı başarmaya yönelik adımların kısa bir listesi olan yöntemdir (process). Çalışmada Mert prosedürü yöntem olarak uygulamış ve geçerli bir kanıta ulaşmıştır.

Mert başlangıçta, Harel ve Sowder'ın (1998) sınıflamasına göre tümevarımsal kanıt şemasına sahip olan bir öğrenci gibi davranmıştır. Çünkü verilen ifadeyi kantlarken bir fonksiyon seçerek, bir örnek için ifadenin 
doğruluğunu göstermeye çalışmıştır. Ancak görüşmecinin "Bu sence yeterli mi, ikna oldun mu ?" gibi sorular yöneltmesi üzerine tekrar düşünmüş ve tanım ve teoremleri kullanarak daha genel bir kanıt yapması gerektiğini fark etmiştir. Mert sürecin büyük bölümünde tümevarımsal kanıt şeması özellikleri göstermiş ancak sonuçta tanımlar arası bağlantıları kurarak amacına yönelik geçişlerle yani dönüşümsel kanıt şemasına uygun olarak geçerli bir kanıt ortaya çıkarmıştır.

Ceren kanıtlarken algoritma kullanmak istemiş ancak elinde hazır bir algoritma olmadığından kanıtlamaya yönelik girişiminde başarılı olamamış, geçerli bir kanıt ortaya çıkaramamıştır. Sadece birbirinden kopuk bazı bilgiler hatırlamaya çalışarak kanıtla ilişkilendirmeye çalışmış ancak bundan herhangi bir sonuç alamamıştır. Çünkü hatırlamaya çalıştığı bilgilerin çoğu eksik ve hatalı bilgilerdir ve de yapması gereken kanıtta kullanabileceği bilgiler değildir. Ceren türevin tanımını doğru ifade edememiş ve kanıtlamada kullanamamıştır. Bir öğrencinin bir tanımı matematiksel olarak yanlış kullanmasının iki nedeni olabilir; tanımladığı kavramla ilgili eksik veya yanlış bilgiye sahip olması ya da genel olarak matematiksel tanımların matematikteki rolünü doğru anlamamasıdır (Edwards\&Ward, 2004).

Ceren, ilk görüşmede kanıt ile ilgili olarak kanıtın tamamen ezber olduğunu ve kanıta kişinin kendinden bir şey katmadığını söylemiştir. Kanıtta öğretmen ne yaparsa onların da aynısını yaptıklarını belirtmiştir. Ceren'in bu düşünceleri ve kanıtlama sürecinin başında sürekli, kitapta var olduğunu düşündüğü, yapılmış kanıta ulaşmaya çalışması otoriter kanıt şemasına sahip olduğunu düşündürmektedir. Çünkü Ceren kanıtın ikna ediciliği ile olarak kendi düşüncesine değil, öğretmen yaptıysa veya kitapta varsa o doğrudur ve ikna edicidir, şeklinde bir düşünceye sahiptir. Kanttlama sürecinde, öğrencinin açıklamasını bir otoriteye dayandırması, öğrencinin konuyu genel olarak ezberlediğinin ve konu hakkında düşünme sürecine girmediğinin bir göstergesidir (Aydoğdu,Toluk ve Olkun, 2003). Ceren aradığı kanıtı kitapta bulamayınca kendisi bir şeyler yapabilmek için uğraşmış ve çok anlamlı olmadığ görülen grafikten (Şekil 2) ifadenin doğruluğunu görmeye çalışmıştır. Bu da Ceren'in aynı zamanda algısal kanıt şemasına sahip kişi özellikleri gösterdiğine işaret etmektedir.

Kanıtlamada kullanılan çok çeşitli stratejiler ve farklı yollar bulunmaktadır. Aynı teorem için birçok kanıt bulunabilir. Hatta iki kişi aynı kanıta ulaşsalar bile kanıtı elde etmek için kullandıkları akıl yürütme yolları çok çeşitli olabilir (Raman, 2003). Öğrenciler de kimi zaman kanitlarken tek bir düşünme biçimine veya tek bir yaklaşıma, tek bir yola bağlı kalmamaktadırlar. Harel ve Sowder (1998) da bir kişinin her zaman tek bir kanıt şemasına sahip olmadığını bazı durumlarda kişinin aynı anda farklı 
şemaları kullanarak kanıtlayabileceğini söylemişlerdir. Raman'ın (2003) çalışması bu görüşü doğrulamaktadır. Benzer şekilde, Aydoğdu, Olkun ve Toluk (2003) bazı öğrencilerin farklı problemlerde tek bir şemayı kullanırken, bazı öğrencilerin de farklı problemlerde farklı şemalar kullandıklarını gözlemişlerdir. Rodriguez (2006) de çalışmasında, matematik öğretmenlerinin dinamik ortamda Cabri kullanarak kanıtlamalarını gözlemiş ve öğretmenlerin birkaç kanıt şemasının özelliklerini gösterdiklerini belirlemiştir. Bu çalışmada ise Mert ve Ceren aynı kanıtta farklı kanıt şemalarının özelliklerini göstermişlerdir.

Ceren'in kanıt yapma yaklaşımıyla ilgili olarak var olan sınıflama çerçevesinde bir şey söylemekte güçlük çekilmiştir. Ceren, görüşmenin büyük bir bölümünde kanıt ile ilgili hiçbir girişimde bulunamamış sadece parça parça, çoğu doğru ve anlamlı olmayan ve kanıtta işine yaramayacak bilgiler hatırlamak için uğraşmıştır. Elinde kitap olması Ceren'e hatırlamaya çalıştığı bilgilere bakması konusunda çok yardımcı olamamıştır. Çünkü Ceren'in söyledikleri ve kanıtlama sürecindeki davranışları aslında ne aradığının, ne yapmak istediğinin bile tam olarak farkında olmadığını göstermektedir. Ceren kitaba bakarken "İşime yarayacak bir şeyler bulur muyum diye bakıyorum" açıklamasını yapmıştır. Kanıtlama çabaları, aklına gelen şeyleri deneme ve kitaptan bulduğu tanımları yazarak "Buradan bir şey çıkar mı acaba?" şeklinde olmuştur. Ceren'in kanıt yapma yaklaşımı var olan sınıflama çerçevesinde prosedürel olarak düşünülebilir. Ancak Ceren için prosedür hazır bir algoritmadır ve algoritmanın olmadığı durumda akıl yürütme, kanıtı kendi çabasıyla ortaya çıkarma konusunda yetersiz kalmaktadır.

Öğrencilerin ikinci görüşmelerindeki kanttlama sürecinde sahip oldukları kanıt şemaları ve kanıt yaklaşımları şekilde özetlenmiştir (Bkz. Şekil 4) 


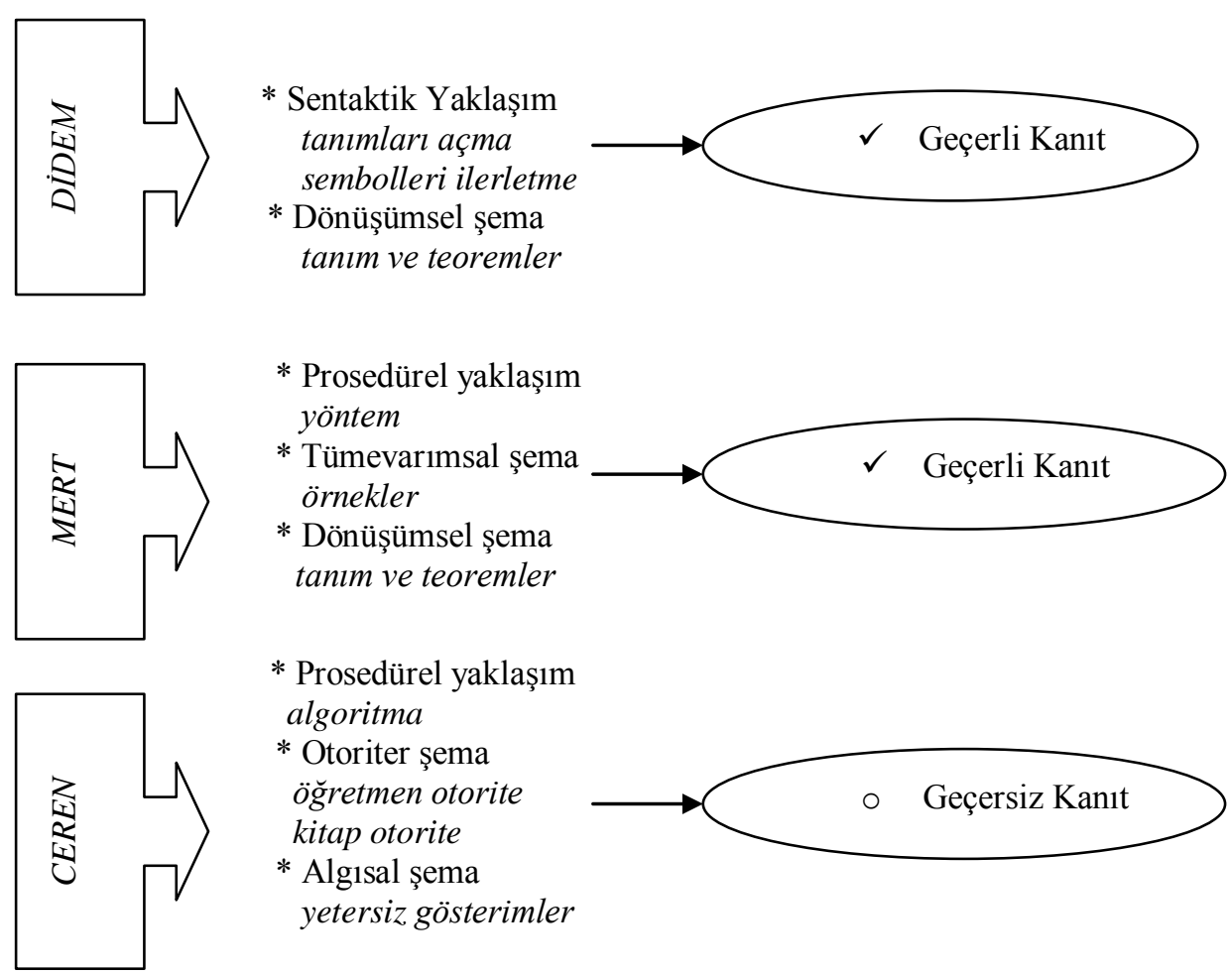

Şekil 4

\section{ÖNERILER}

$\mathrm{Bu}$ çalışma, üç öğrenciyle Analize Giriş II dersi kapsamında gerçekleştirilmiştir. Ögrencilerle yapılan ilk görüşmede, kanıt yapma ile ilgili genel düşünceleri belirlenmiş, ikinci görüşmede kanıtlama süreçlerinin incelenmesi amaciyla, verilen bir matematiksel ifadeyi kanitlamaları istenmiştir. Sonuçlar araştırmanın problemlerine yanıt olmasının yanında yeni çalışmalarda araştırılacak problemler ortaya çıkarmıştır.

Çalışmanın sonuçları, sadece üç öğrenciyle ve tek bir ifadenin kanıtlanması üzerinde çalışılarak elde edildiği için sınırlıdır. Ancak farklı başarı seviyesindeki öğrencilerin kanıtla ilgili düşünceleri, kanıt şemaları ve kanıt yapma yaklaşımları ile ilgili olarak açıklayıcı bilgiler ortaya koymaktadır. Daha çok katılımcıyla ve farklı kanıt görevleri verilerek yapılacak çalışmalar, belki yeni kanıt şemaları ve kanıt yapma yaklaşımları 
ortaya çıkarabilir. Bu çalışmada, öğrencilerin kanıt şemaları ve kanıt yapma yaklaşımları var olan şema ve yaklaşımlara göre sınıflandırılmıştır. Didem ve Mert'in kanıt yapma yaklaşımları net bir şekilde görülmüş ancak Ceren'in kanıt yapma yaklaşımını sınıflamada güçlük çekilmiştir.

Crawford (1994; akt. Solomon, 2006) birinci sinıf matematik öğrencilerinin, matematiği ezbere öğrenme işi olarak gördügünü gözlemiştir. Moore (1994) üniversitede verdiği derslerde bazı çalışmalar yapmış ve öğrencilerin kanıtı, prosedürel ve yapılması gereken bir dizi aşama olarak gördüğünü belirlemiştir. Gray ve diğerleri (1999) prosedürel yaklaşımdaki öğrencilerin ileri matematiksel düşünmede daha az başarılı olduklarını bulmuşlardır (akt. Knapp, 2005). Bu çalışmada da prosedürel yaklaşıma sahip olan Mert ve Ceren kanıtı yapmada daha çok güçlük çekmişlerdir. Ceren sonuçta geçerli kanıta ulaşamamış, Mert ise sürecin sonunda, biraz da araştırmacının yönlendirmesiyle geçerli bir kanıta ulaşmıştır. Derste, diğer katılımcılara göre daha başarılı bir öğrenci olan Didem ise zorlanmadan geçerli bir kanıt ortaya çıkarmıştır. Öğrencilerin kanıtlamada, ders başarılarına paralel bir başarı sergilemeleri matematiğe yaklaşımlarıyla kanıt yapma yaklaşımlarının ilişkili olduğunu düşündürmektedir. Mert ve Ceren yapılan görüşmede kanıtlamayı ezbere bir iş olarak gördüklerini belirtmişler, özellikle Ceren kanıt yapmada kendilerinden hiçbir şey katmadıklarını öğretmenin söylediklerini aynen yaptıklarını ifade etmiştir. Bu yaklaşıma sahip olmalarının, kanıtlamadaki başarılarını etkilediği düşünülebilir ve bununla ilgili daha kapsamlı çalışmalar yapılabilir. Öğrencilerin genel olarak matematiğe yaklaşımları ve bunun ders başarılarına etkisi de araştırılabilir.

Öğrenciler kanıtlama ve formal matematikle ilk defa üniversitede karşılaşmaktadırlar. Bu durum matematiksel dile alışmaları, daha soyut ve üst düzey düşünmeleri, formal matematiği anlamaları konusunda güçlüklere neden olmaktadır. Yurtdışında bazı üniversitelerde, lisedeki sistemden gelip ileri matematiksel düşünceye alışmakta ve formal matematiği anlamakta zorlanan öğrencilere yönelik geçiş dersleri bulunmaktadır (Knapp, 2005). Bu derslerde öğrencilere matematiğin aksiyomatik yapısı, kanıtın ne olduğu ve kanitlama yöntemleri verilmekte ve ileri düzey matematik derslerine hazırlanmaları, geçmişteki eksikleri tamamlamaları sağlanmaktadır. Ülkemizde de böyle bir çalışmanın yapılması, bu tür geçiş derslerinin konulması düşünülebilir. 


\section{KAYNAKLAR}

Almeida, D. (2000). A survey of mathematics undergraduates' interaction with proof: some implications form mathematics education. International Journal of Mathematical Education in Science and Technology, 31(6), 869-890

Almeida, D. (2003). Engendering proof attitudes: Can the genesis of mathematical knowledge teach us anything?. International Journal of Mathematical Education in Science and Technology, 34(4), 479-488.

Aydoğdu, T. Olkun, S., \& Toluk, Z. (2003). İlköğretim öğrencilerinin çözdükleri matematik problemlerini kanttlama süreçleri, Eğitim Araştırmaları, 4(12), 64-74.

Dreyfus, T. (1999). Why Johnny Can't Prove. Educational Studies in Mathematics, 38(1), 85-109

Edwards, B.S. \& Ward, M.B.( 2004). Surprises from Mathematics Education Research: Student (Mis)use of Mathematical Definitions. The American Mathematical Monthly, 111, 411-424.

Güven, B., Çelik, D. ve Karataş, İ. (2005). Ortaöğretimdeki Çocukların Matematiksel İspat Yapabilme Durumlarının İncelenmesi. Çăgdaş Ĕ̈itim Dergisi.,30, 319,

Harel, G.\& Sowder, L. (1998). Students' proof schemes. In E. Dubinsky, A. Schoenfeld, \& J. Kaput (Eds.), Research on Collegiate Mathematics Education, III , 234-283. AMS.

Harel, G., \& Sowder, L (2007). Toward comprehensive perspectives on learning and teaching proof, In F. Lester (Ed.), Handbook of Research on Teaching and Learning Mathematics (2nd Ed.). Greenwich, CT: Information Age Publishing.

Heinze, A. \& Reiss, K. (2003). Reasoning and proof: Methodological knowledge as a component of proof competence. In M.A. Mariotti (Ed.), Proceedings of the ThirdConference of the European Society for Research in Mathematics Education, Bellaria, Italy.

Housman, D.\& Porter, M. (2003). Proof schemes and learning strategies of above average mathematics students. Educational Studies in Mathematics, 53, 139-158

Jones, K. (1997). Student-Teachers' Conceptions of Mathematical Proof, Mathematics Education Review, 9, 16-24 
Jones, K. (2000). The student experience of mathematical proof at university level, International Journal of Mathematical Education in Science and Technology, 31,1, 53-60.

Knapp, J.(2005). Learning to prove in order to prove to learn. [Online]:Retrieved on 16-April-2007 at URL: http://mathpost.asu.edu/ sjgm/issues/2005_spring/SJGM_knapp.pdf

Knuth, E. J. (2002). Teachers' Conceptions of Proof in the Context of Secondary School Mathematics, Journal of Mathematics Teacher Education, 5, 1, 61-88

Moore, R.C. (1994). Making the transition to formal proof . Educational Studies in Mathematics ,27, 249-266.

Moralı, S.,Uğurel, I., Türnüklü, E. \& Yeşildere, S. (2006). Matematik öğretmen adaylarının ispat yapmaya yönelik görüşleri. Kastamonu Ĕ̈itim Dergisi, 14, 1, 147-160

Özer, Ö. \& Arıkan, A. (2002). Lise matematik derslerinde öğrencilerin ispat yapabilme düzeyleri. V.Ulusal Fen Bilimleri ve Matematik Eğitimi Kongresi, 16-18 Eylül Ankara, Bildiriler Kitabı, II, 1083-1089.

Raman, M. (2001). Beliefs about proof in collegiate calculus, in Robert Speiser (Ed.), Proceedings of the Twenty Second Annual Meeting, North American Chapter for the International Group for the Psychology of Mathematics Education, Snowbird, Utah.

Raman, M. J. (2002). Proof and Justification in Collegiate Calculus. Doctoral dissertation, University of California: Berkeley

Raman, M.(2003). Key ideas: What are they and how can they help us understand how people view proof?. Educational Studies in Mathematics, 52, 319-325.

Recio, A. M. \& Godino, J. D.(2001). Instutional and Personal Meanings of Mathematical Proof, Educational Studies in Mathematics, 48, 1,83-89

Rodriguez, A.V.R. (2006). Ways of reasoning and types of proofs that mathematics teachers show in technology-enhanced instruction. Proceedings of the 28th annual meeting of the North American Chapter of the International Group for the Psychology of Mathematics Education.

Solomon, Y. (2006). Deficit or difference? The role of students' epistemologies of mathematics in their interactions with proof, Educational Studies in Mathematics, 61(3), 373-393. 
Stylianides, G. J., Stylianides, A. J., \& Philippou, G.N. (2007). Preservice teachers' knowledge of proof by mathematical induction. Journal of Mathematics Teacher Education, 10, 145-166.

Weber, K. (2001). Student difficulty in constructing proof: The need for strategic knowledge. Educational Studies in Mathematics, 48(1), 101119.

Weber, K. \& Alcock, L.J., (2004). Semantic and syntactic proof productions. Educational Studies in Mathematics, 56(3), 209-234.

Weber, K. (2004a). Describing problem-solving processes of undergraduates when constructing proofs. . [Online]: Retrieved on 15-May-2007 at URL: http://www.icmeorganisers.dk/tsg18/S31Weber.pdf

Weber, K. (2004b). A Framework for Describing the Processes that Undergraduates Use to Construct Proofs. In M. J.Hoines \& A. B. Fuglestad (Eds.) International Group for the Psychology of Mathematics Education, 28th, Bergen, Norway, 14-18,

Weber, K. (2004c). Traditional instruction in advanced mathematics courses: a case study of one professor's lectures and proofs in an introductory real analysis course. Journal of Mathematical Behavior 23, 115-133. 